\title{
Entropy, Free Radical and Life System
}

\author{
Honghu Li, Junhua Hou \\ College of Physics and Information Engineering, Shanxi Normal University, Linfen, China \\ Email: jhhou@126.com
}

How to cite this paper: Li, H.H. and Hou, J.H. (2016) Entropy, Free Radical and Life System. Open Journal of Biophysics, 6, 8389.

http://dx.doi.org/10.4236/ojbiphy.2016.64009

Received: August 8, 2016

Accepted: August 26, 2016

Published: August 30, 2016

Copyright $\odot 2016$ by authors and Scientific Research Publishing Inc. This work is licensed under the Creative Commons Attribution International License (CC BY 4.0).

http://creativecommons.org/licenses/by/4.0/

\begin{abstract}
Effects of entropy and free radical in life system are elucidated. The results indicate that living organism can maintain normal activities only if a suitable free radicals inside living organism can be guaranteed. Excessive free radical should be eliminated to reduce entropy in living organism. Some ways provided to eliminate excessive free radical, reduce entropy and keep health.
\end{abstract}

\section{Keywords}

Entropy, Free Radical, Living Organisms

\section{Introduction}

The problems of energy shortages, food shortages and environment pollution have got increasingly concern of attention for people with the accelerating development of society. Entropy theory has gradually showed its common sense and received concern from scholars in each circle during its birth and development. It is of great necessity and importance to further study and explores the entropy theory and rule.

Some researchers point out that essential feature of real system is irreversible, which can be understood with the second law of thermodynamics. The real system is always related to temperature and thermal phenomenon. The entropy theory has been proposed to predict the potential threat of living environment earliest. Environmental protection problem has begun to be realized by people.

It has proved that the potential threats of human living environment come from the excessive free radicals in environment and living organisms [1]. Early in 1960's, western medical scientists have found that human health was influenced by the excessive free radicals in environment and living organisms. The harm of the excessive free radicals has also been further proved by the development of free radical chemistry in recent years. The problems of human health threats from cell damage caused by free radicals 
have become important and fundamental research projects.

\section{The Relation between Entropy Theory and Life System}

One of the basic characteristic of life system is metabolism. The energy metabolism due to series of energy transfer of metabolism is another basic characteristic of living organisms.

Entropy is a basic state function of thermodynamic system [2]. The Germany scientist R. Clausius put forward the concept of "entropy" in the study of thermodynamic energy phenomenon. After that he put forward the principle of entropy increase and promote the development of thermodynamic. In 1977, L. Boltzmann elaborated the relationship between entropy and thermodynamic probability [3]. Following that, the theory of Clausius entropy and Boltzmann entropy came out. Clausius entropy explain the second law of thermodynamics in Macro and Boltzmann entropy explain that in Microcosmic... The concept of entropy is gaining more and more attention and application in thermodynamics and extended to other areas gradually.

As a state function, entropy it can be positive or negative. In 1943, Erwin Schrodinger, first explained life essence with thermodynamics and quantum mechanics theory and put forward the negentropy in his speech in Trinity College of Dublin. In view of thermodynamics, life system is an open system. Based on the thermodynamics of irreversible process, the entropy change of meta-process in living organisms in this open system can be written as:

$$
\mathrm{d} S=\mathrm{d}_{\mathrm{e}} S+\mathrm{d}_{\mathrm{i}} S
$$

In above, $\mathrm{d}_{\mathrm{e}} S$ refers to the net entropy imported from environment by metabolic activity, which can be positive or negative. The $\mathrm{d}_{\mathrm{i}} S$ refers to entropy change of inner body due to various irreversible processes of living organisms, which is always positive. It can be determined whether living organism is normal or not by Equation (1). There are three conditions:

1) If $\frac{\mathrm{d} S}{\mathrm{~d} t}>0$, then $\frac{\mathrm{d}_{\mathrm{i}} S}{\mathrm{~d} t}>-\frac{\mathrm{d}_{\mathrm{e}} S}{\mathrm{~d} t}$.

In this condition, the imported negative entropy of living organisms can not counteract the inner entropy, the entropy increased, and the living organisms face to death, disease or aging.

2) If $\frac{\mathrm{d} S}{\mathrm{~d} t}=0$, then $\frac{\mathrm{d}_{\mathrm{i}} S}{\mathrm{~d} t}=-\frac{\mathrm{d}_{\mathrm{e}} S}{\mathrm{~d} t}$.

The imported negative entropy of living organisms can counteract the inner entropy, and the living organisms are in normal and stable condition.

3) If $\frac{\mathrm{d} S}{\mathrm{~d} t}<0$, then $\frac{\mathrm{d}_{\mathrm{i}} S}{\mathrm{~d} t}<-\frac{\mathrm{d}_{\mathrm{e}} S}{\mathrm{~d} t}$.

The imported negative entropy of living organisms is big enough, and then the living organisms become more orderly and energetic. The living organisms will be further developed.

According to the discussion above, it is known that the imported negative entropy in 
the system is of close relationship for the movement of living organisms. Because living system is an open system, the living organisms draw off entropy gradually, and absorb negative entropy in suitable ways (such as medical treatment or psychotherapy), in order to form substance negative entropy flow and information negative entropy flow etc. The living organisms can then increase inner order gradually through energy movement and substance circulation.

Now the entropy change will be discussed. Suppose living organisms is not a constant-temperature system, so that the movement of living organism is not an isothermal process. It can be understood that the temperature change of living organism is insignificant during development, the temperature in each stage and even each moment is different, so this supposition is absolutely reasonable. Under this supposition, the entropy change will be discussed. It is known that life system is a far-from-equilibrium system, and normally absorbed energy of living organisms is always greater than emitted energy. So that the energy transfers in living organisms must be $Q \geq 0$. The entropy change of living organisms is $\Delta_{\mathrm{i}} S=\frac{Q}{T} \geq 0$. Because certain energy is needed to consume to maintain inner metabolism and heat dissipation to the outside, if can be inferred $\Delta S<0$. Normally, living organisms always process and develop. While the living organisms move to aging and sick condition, the inner entropy change is $\Delta S>0$. But why the entropy change is large than zero in living organism at this moment? What is the relationship between this entropy change, structure and inner composition of living organisms? In below the life system will be discussed from the aspect of free radical, and the relationship between entropy and free radical will be explained.

\section{The Relation between Free Radical and Life System}

Living organisms needs metabolism, mainly biochemical reactions. Free radical is produced during metabolism, but there are many substances functioning as scavengers for free radical in inner body, so normally, the formation and remove of free radical are in a dynamic balance [4]. Free radical in inner body remains a certain concentration. Namely it is necessary for living organism to main normal living activities with certain amount of free radicals. When some being sick in the middle age, the ability of emitting free radical is decreasing, which makes inner free radical increase greatly and the concentration of free radical increase. For example the inner oxygen free radical and superoxide anion etc. will exceed normal level. These excessive free radical influenced body function, which results into the occurrence of various diseases, such as lipid peroxide resulted from free radical, cell mutation resulted from DNA damage etc. Therefore, how does free radical produce? How does it influence living organisms? What follows are explorations from the aspect of chemistry.

It is known that alkanes and oxygen can have obvious reaction under the condition of light or heating, and produce alkane oxidation and the oxidation of hydrogen. For example, $\mathrm{CH}_{4}$ and $\mathrm{CL}_{2}$ can produce $\mathrm{HCL}$ and $\mathrm{CH}_{2} \mathrm{CL}$ in chemical reaction.

$$
\mathrm{CH}_{4}+\mathrm{CL}_{2} \underset{\text { or } \Delta}{\stackrel{h v}{\longrightarrow}} \mathrm{HCL}+\mathrm{CH}_{3} \mathrm{CL}
$$


Among them, $h v$ refers to light, and $\Delta$ Refers to heat.

It is known that normally the organic reactions are complex. One needs to know the reaction process in order to grasp reaction nature and control and get use of this reaction. The chemists proposed the reaction mechanism hypothesis [5]. For example, they put forward the following hypothesis as for oxygen and methane reaction process.

$$
\begin{aligned}
& \mathrm{CL}_{2} \stackrel{h v}{\stackrel{h r \Delta}{\longrightarrow}} 2 \mathrm{CL} \text {. Looping starting } \\
& \left.\begin{array}{l}
\mathrm{CL} \cdot+\mathrm{CH}_{4} \longrightarrow \rightarrow \mathrm{CH}_{3} \cdot+\mathrm{HCL} \\
\mathrm{CH}_{3}+\mathrm{CL}_{2} \longrightarrow \mathrm{CH}_{3} \mathrm{CL}+\mathrm{CL} \cdot
\end{array}\right\} \quad \text { Looping proliferation }
\end{aligned}
$$

Repeat the (4) and (5) reaction.

$$
\left.\begin{array}{l}
\mathrm{CH}_{3}+\mathrm{CL} \cdot \longrightarrow \mathrm{CH}_{3} \mathrm{CL} \\
\mathrm{CH}_{3}+\mathrm{CH}_{3} \cdot \longrightarrow \mathrm{CH}_{3} \mathrm{CH}_{3} \\
\mathrm{CL} \cdot+\mathrm{CL} \cdot \longrightarrow+\mathrm{CL}_{2}
\end{array}\right\} \quad \text { Looping destination }
$$

The first reaction step $\mathrm{A}$ is that $\mathrm{CL}_{2}$ resolves into two $\mathrm{CL}$ atomics after getting energy.

$$
: \ddot{\mathrm{CL}}: \ddot{\mathrm{CL}}:+ \text { Energy } \rightarrow: \ddot{\mathrm{CL}} \cdot+\stackrel{\ddot{\mathrm{CL}}}{.}
$$

The two parts after resolve, each CL atomic keeps an electronic. We call the atom or atom group with single or uncoupled electronic after resolve the free radical.

Light or heat is needed when CL molecular resolves into CL atomic, namely resolve needs energy. At this moment free radical absorbs energy, and its single electronic has a strong tendency of pairing. Therefore free radical is really active, which can incur looping reaction. In looping reaction, formula (4) and (5) are the most important steps of free radical reaction, which continually produce new free radicals and products that makes the whole process circulate. However, active and low-concentration free radicals have the chance of collision, like formula (6), (7) and (8). When these collisions occurred, looping reaction will end. However, there has a small possibility of collision, and (4) and (5) steps are the main parts in the whole looping reaction.

After knowing the free radical and looping reaction of it, analysis will be made based on living organisms.

Free radicals have a positive effect and negative effect for living organisms we referred above, which is determined by the concentration of free radicals. When the free radical in living organism is suitable, it is favorable for living organisms, which may motivate some reaction process or improve the activity of enzymes. At the same time, antioxidant system activities will be improved. But when life system is invaded by bacteria, inflammation will occur. In the late period of inflammation, monocytes will enter inflammation area. After the entering, the monocytes will become phagocytes. During devouring bacteria process of these phagocytes, the so-called sudden process will produce amounts of superoxide anion free radical and hydroxyl free radical etc, which function as killing bacteria and promoting the degradation [6]. This is the positive aspect of free radical for living organisms. As a whole, excessive free radical have more negative effects than positive effects for living organism. The following discussion is 
mainly the damage of free radicals for living organism.

\subsection{The Lipid Peroxidation of Oxygen Free Radical}

Oxygen free radical we referred above is one of important free radicals for living organisms, and it can incur lipid peroxidation. Biofilm in living organism contains various unsaturated fatty acids, when it has free radical initiator and oxygen, it may occur oxidation. This oxidation process is called the lipid peroxidation. The general reaction is as follows:

A $\quad\left(-\mathrm{CH}=\mathrm{CH}-\mathrm{CH}_{2}-\right)+\mathrm{R} \cdot \longrightarrow(-\mathrm{CH}=\mathrm{CH}-\dot{\mathrm{CH}}-)+\mathrm{RH}$

B $(-\mathrm{CH}=\mathrm{CH}-\dot{\mathrm{CH}}-)+\mathrm{O}_{2} \cdot \longrightarrow(-\mathrm{CH}=\mathrm{CH}-\underset{\substack{1 \\ \mathrm{O}-\mathrm{O}}}{\mathrm{CH}-})$

$$
\begin{aligned}
& \mathrm{C} \quad\left(-\mathrm{CH}=\mathrm{CH}-\underset{\mathrm{O}-\mathrm{O}}{\mathrm{C}}-\mathrm{CH}-\left(-\mathrm{CH}=\mathrm{CH}-\mathrm{CH}_{2}-\right)\right. \\
& \longrightarrow(-\mathrm{CH}=\mathrm{CH}-\underset{\mathrm{O}-\mathrm{OH}}{\mathrm{CH}}-)+(-\mathrm{CH}=\mathrm{CH}-\dot{\mathrm{CH}}-)
\end{aligned}
$$

In above, $\mathrm{R}$ - is the initiator of free radical. In formula (9), $\mathrm{R}$ - takes away $\mathrm{H}$ from unsaturated fatty acid molecules (I), and produces free radical (II). Free radical (II) absorbs oxygen and forms fatty acid peroxide genes (III) in formula (10). The fatty acid peroxide genes (III) react with another molecule (I), and produce another free radical (II) and an unsaturated hydrogenated oxide (IV) in formula (11). It is obvious that a small amount of free radical initiator may result into looping reaction for thousands of molecules. Through the looping reaction, fine and orderly structures in biofilm of unsaturated fatty acids can incur huge disorders because of lipid peroxidation.

\subsection{The Toxicity of Superoxide Anion Free Radical}

Superoxide anion free radical $\left(\mathrm{O}_{2}^{-} \cdot\right)$ is the product of many enzyme reactions in cell, such as zanthine oxidase, aldehyde oxidase and galactose oxidase etc. These superoxide anion free radicals can function as weak base and become electronic donor, namely reductive agent. For example, it can reduce cytochrome $c$, which is a kind of protein with heme and reduce $\mathrm{Fe}^{3+}$ in heme center into $\mathrm{Fe}^{2+}$.

$$
\text { Cytochrome } \mathrm{c}\left(\mathrm{Fe}^{3+}\right)+\mathrm{O}_{2}^{-} \cdot \longrightarrow \mathrm{O}_{2}+\text { Cytochrome } \mathrm{c}\left(\mathrm{Fe}^{2+}\right)
$$

The produced ferrous iron is toxic. On the other hand, $\mathrm{O}_{2}^{-}$. which is the electronic accepter can function as weak oxidant and oxidize resistible blood clots.

Resistible blood clots $+\mathrm{O}_{2}^{-} \cdot+\mathrm{H}^{+} \longrightarrow \mathrm{H}_{2} \mathrm{O}_{2}+$ free radical of resistible blood 
The produced $\mathrm{H}_{2} \mathrm{O}_{2}$ is weak oxidant, which can oxidate $-\mathrm{SH}$ in small amount of enzymes and lose energy, and also damage body cell.

Other free radicals also have damages. For example, free radicals can incur hydrogen bond fracture in DNA of cell, and make the alkali bases degrade and main looping unwind. All nucleic acid composition may be attacked by free radicals, whose attack may be mended by some special mechanism. However, it may cause permanent damage. Therefore, free radical is of great relationship with the living organism. Excessive free radical incurs the aging and disease of living organisms, and from the discussion of entropy theory and life system. It is known that it may be aging and disease if $\Delta S>0$ in living organism. What follows is the discussion of the relationship of them.

\section{The Relationship of Entropy and Free Radical}

It is known that free radical receives energy during degradation, and its single electron has a great tendency of pairing. Therefore free radical has great activities, which can incur a series of looping reactions. Two results incurred by looping reaction will be discussed. On the one hand, different materials are produced during looping reaction, for example

$$
(-\mathrm{CH}=\underset{\mathrm{O}}{\mathrm{CH}}-\underset{\mathrm{OH}}{\mathrm{CH}}-)
$$

produced in lipid peroxidation and

$$
\left(-\mathrm{CH}=\mathrm{CH}-\mathrm{CH}_{2}-\right)
$$

in living organism. The two products are different materials, namely it has new material during this reaction process. New cell in living organism will increase because of new materials.

On the other hand, the produced harmful material will damage cell during looping reaction, which make the structure and function of cell change. The cell with changed structure and function in living organisms will no longer obey the control and change mechanism of cell growth and degradation, namely it shows great autonomy and this process is irreversible, and it has genetic effect for daughter cells. The uncontrolled increase of cell because of structure and function change may lead to its cell change, and grow in healthy tissue. Cell numbers will inflate in the form of index in each cell breeding and degradation. Therefore, with the function of changed cells for structure and function change, cell number increases more obviously in this living organism than in normal living organism.

It is known from the above analysis that cell categories will increase once there is excessive free radicals. Under the condition that cell categories increase and cell numbers increase infinitely, the categories and numbers of atomic and molecular which are composed of various cells will also increase. Namely microscopic particles numbers will increase greatly. Thermal motion category and intensity of microscopic particles increase more greatly than that before, and the chaos degree in living organism is greater than that before. So the entropy increases in living organism. Considering the Boltzmann 
formula, under the condition that various microscopic particles numbers in living organism will increase greatly, microscopic state numbers $W_{c}$ (change) of various microscopic particles corresponding to macroscopic state increase more greatly than that of original microscopic state $W_{o}$ (original), namely

$$
\frac{W_{c}}{W_{o}}>1
$$

It can be seen that

$$
\Delta S=S_{c}-S_{o}=k \ln W_{c}-k \ln W_{o}=k \ln \frac{W_{c}}{W_{o}}>0
$$

from Boltzmann relationship. Namely after free radical damages cell, entropy change in living organism $\Delta S>0$, which results into the aging and disease of living organism.

\section{Conclusions}

Life system is discussed based on entropy theory and free radical theory. The connection between entropy and free radical with life system as bridge is explained. The entropy with chemistry and biology aspects is used for study living organism. In order to maintain living organism normal activities, suitable free radicals inside living organism should be guaranteed on the one hand. On the other hand, excessive free radical must be eliminated to reduce entropy in living organism. There are some ways to clean the excessive free radical to keep $\Delta S<0$ :

1) Fresh: drink clean water, have fresh food. Eat less food which is artificial, overprocessing and not fresh.

2) Clean: No smoking, no drinking. Breath fresh air. No Drug abuse. Avoid expose to sunlight for a long time. Stay away from pollution source.

3) Relax: Irregular life, stress, tension and so on will cause the sympathetic nerve disordered and the white blood cells to produce excessive free radicals, so we should cut down pressure properly.

4) Energy: More exercise will help eliminate excessive free radical.

\section{References}

[1] Jin, X.H. (2002) Environmental Free Radical and Human Health. Chemistry World, 5, 277-279.

[2] Liu, C.Y. and Zhao, L.N. (2012) History of Entropy and Its Role in Biomedical Signal anAlysis. Beijing Biomedical Engineering, 5, 539-543.

[3] Li, J.L. and Zhao, L.N. (2011) The Relationship between Clausius Entropy and Boltzmann Entropy. Changshu Institute of Technology Press, Changshu.

[4] Zhen, R.L. (1993) Free Radical Life Science Development. Atomic Press, Beijing.

[5] Wang, J.T. and Hu, Q.M. (1993) Organic Chemistry. Naikai University Press, Tianjin.

[6] Zhen, R.L. (1992) Free Radical Biology. Higher Education Press, Beijing. 
Submit or recommend next manuscript to SCIRP and we will provide best service for you:

Accepting pre-submission inquiries through Email, Facebook, LinkedIn, Twitter, etc. A wide selection of journals (inclusive of 9 subjects, more than 200 journals)

Providing 24-hour high-quality service

User-friendly online submission system

Fair and swift peer-review system

Efficient typesetting and proofreading procedure

Display of the result of downloads and visits, as well as the number of cited articles

Maximum dissemination of your research work

Submit your manuscript at: http://papersubmission.scirp.org/ 